\title{
Evaluating the sterility of orthodontic materials as received from the manufacturer and that exposed to clinic environment - in vitro study
}

\author{
Musaddique, Shafi Sayyed *; Ajit, Kalia *; Ashwith, Hegde *; Nasim, Mirdehghan *; Faraaz Mohamed, Ali Khan * \\ * M.A.Rangoonwala College Of Dental Sciences and Research Centre, Pune, India
}

\begin{abstract}
Introduction: Sterilization in orthodontics has been discussed and stressed over times in the dental literature. Sterility of orthodontic materials should be of prime interest to the orthodontist as a health care professional and he should take appropriate measures to prevent the risk of cross infection.

Aim: To evaluate the sterility of orthodontic materials as received from the manufacturer and that exposed to clinic environment for 6 months. Materials and methods: The sterility of orthodontic materials "as received" from the manufacturer and "clinically exposed" (unused materials stored in the clinic environment for a period of 6 months) was microbiologically evaluated (universal \& conventional PCR). The materials which were included in this study were the sealed and unsealed orthodontic archwires, molar bands, elastomeric module, stainless steel bracket, coil spring and tungsten carbide burs of various brands (American Orthodontics, 3M Unitek, Ormco, Orthosystems, G\&H, Modern Orthodontics, SS white etc).

Results: After universal and conventional PCR, the detection of micro-organisms in all materials was significantly higher in the clinically exposed samples compared to as received samples from manufacturers $(\mathrm{P}<0.001)$. The detection of micro-organisms in all orthodontic wires is significantly higher in the unsealed samples compared to sealed samples $(\mathrm{P}<0.001)$. In universal PCR, the detection of microorganisms in all materials (Coil spring, E-chain, Elastomeric, Molar brands, Tungsten carbide) except for SS brackets is significantly higher in both as received and clinically exposed samples.

Conclusion: After universal and conventional PCR, we conclude that bacteria were present on almost all orthodontic materials "as received from the manufacturers" and that exposed to a clinical environment. Therefore all materials should be sterilized before use in patients.

Musaddique SS, Ajit K, Ashwith H,Nasim M, Faraaz Mohamed AK. Evaluating the sterility of orthodontic materials as received from the manufacturer and that exposed to clinic environment - in vitro study. South Eur J Orthod Dentofac Res. 2018;5(2):13-20.
\end{abstract}

Submitted: May 3, 2018; Revised: October 7, 2018; Published: September 15, 2018

\section{INTRODUCTION}

Sterilization in orthodontics has been discussed and stressed over times in the dental literature, but the growth of interest in infection control dates back to the advent of acquired immunodeficiency syndrome (AIDS) in 1981. Epidemiology of Hepatitis B provides most of the data on which concepts of

Corresponding Author:

Faraaz Mohamed Ali Khan

Department of Orthodontics and Dentofacial Orthopaedics,

M.A.Rangoonwala College of Dental Sciences \& Research Centre,

Pune-1, India

e-mail: faraazkhan07@yahoo.com operatory infection control are based, and this has led to the hypothesis that a standard set of infection control strategies should be sufficient for preventing hepatitis B, AIDS, and other blood-borne viral diseases. ${ }^{1,2}$

Dental professionals have a duty of care to their patients and must take appropriate precautions with respect to protecting patients and the team from the risks of cross-infection by following sterilization protocols. Sterilization indicates the erroneous use of this word and the substitution of sterilization for disinfection, imparts false security in the clinic. So the distinction between these terms is important. ${ }^{3}$

Orthodontics is associated with younger patients when compared to other specialties. Some orthodontists are reckless in controlling 
infection by considering orthodontics as a non-invasive specialty. ${ }^{4}$ This thought is a big mistake, as orthodontists see blood in the patient's mouth at an average of ten times a week, meaning that orthodontics cannot be considered as non-invasive. ${ }^{4}$

Although all instruments used in orthodontics, as in dentistry, are sterilized before use, the same is not true for orthodontic archwires, brackets, bands, and impression trays which fall in the semi-critical objects. These are used "as received" from the manufacturers, often with the assumption that the level of hygiene in the manufacturing process and subsequent transportation is sufficient to allow for clinical use.

The orthodontist, therefore, should be aware of and follow widely accepted and used, systematic protocols for sterilization. The advice sheet on infection control formulated by the department of health in the United Kingdom proposes a threestage protocol to sterilization, which includes pre-sterilization cleaning, sterilization and storage. ${ }^{3}$

The aim of the study was to evaluate the sterility of orthodontic materials as received from the manufacturer and that exposed to a clinic environment for 6 months. The null hypothesis states that all the materials as received from the manufacturer and that after storage remains sterile.

\section{MATERIALS AND METHODS}

In the present study, the sterility of orthodontic materials "as received" from the manufacturer and "clinically exposed" (unused materials stored in the clinic environment for a period of 6 months) has been evaluated.

\section{Sample size and design}

The study consisted of 360 samples with 10 samples of each orthodontic material. 7 different orthodontic materials were chosen which were evaluated at two-time intervals. First, as obtained from newly arrived stock (Group 1) and second after storage for 6 months (Group 2). Among orthodontic archwires, 3 manufacturers were chosen for sealed and 3 manufacturers for unsealed products with 10 samples of each manufacturer. (Figure 1a, 1b, 1c)

The study was divided into two parts:

In part 1 we investigated the sterility of various orthodontic materials as received directly from the different manufacturers. These items were listed as group one (Table 1 ) and were obtained from newly arrived stock from different manufacturers in the Department of Orthodontics and Dentofacial Orthopedics.

In part 2 we investigated the sterility or possible microbial contamination of those new orthodontic materials that had been stored in the department and had been exposed to the everyday clinical environment. (Figure 2) (Table 1)

All items were transported to the Department of Molecular Biology and Immunology for microbiologic investigation.

The samples were transferred to autoclavable pouches for transportation. This transfer to the pouches was strictly done by

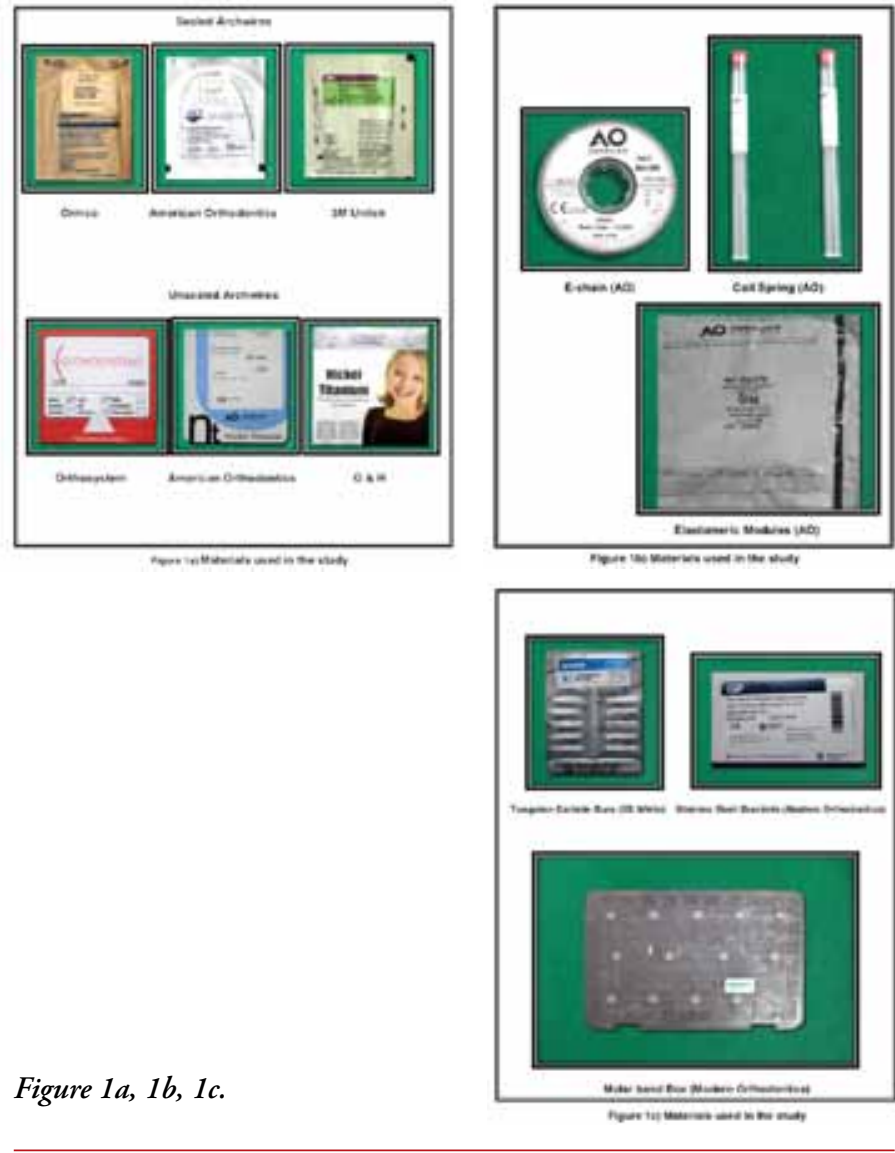

Figure 2.

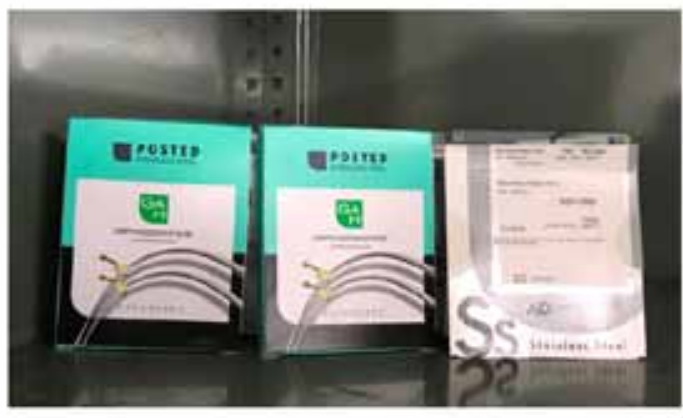

Materials stored for 6 months in the clinical emvironment in the

department of orthodontes and dentolacial orthpedics

Figure 2) Storage of some of the materials

the use of sterile instruments and with the use of sterile gloves to eliminate the risk of cross-contamination from the investigator. (Figure 3a, 3b, 3c) Then these pouches were delivered to the Department of Molecular Biology and Immunology for analyzing microbial contamination immediately without any storage or waiting period, a procedure of analyzing the bacteria was performed. DNA extraction was done and stored in -200C. Molecular analysis was carried out by Polymerase chain reaction (PCR).

This whole genome extract from all clinical samples of group 1 and 2 were used as templates in each round of PCR method 
Table 1. Materials in Group 1 - "as received" and Group 2 - "linically exposed".

\begin{tabular}{|c|c|c|c|c|}
\hline No. & Materials & $\begin{array}{l}\text { Group I } \\
\text { As received }\end{array}$ & $\begin{array}{l}\text { Group II } \\
\text { Clinically } \\
\text { exposed }\end{array}$ & Manufactures \\
\hline \multirow[t]{14}{*}{1.} & $\begin{array}{l}\text { Archwires } \\
\text { a. Sealed archwires }\end{array}$ & & & \\
\hline & .019 x.025-in stainless steel archwire & 10 & 10 & $\mathrm{AO}$ \\
\hline & $.019 \times .025$-in stainless steel archwire & 10 & 10 & ORMCO \\
\hline & .019 x.025-in stainless steel archwire & 10 & 10 & $3 \mathrm{M}$ unitek \\
\hline & $.016 "$-in nickel-titanium archwire & 10 & 10 & $3 \mathrm{M}$ unitek \\
\hline & $.016 "$-in nickel-titanium archwire & 10 & 10 & ORMCO \\
\hline & $.016 "$-in nickel-titanium archwire & 10 & 10 & $\mathrm{AO}$ \\
\hline & \multicolumn{4}{|l|}{ b. Unsealed archwires } \\
\hline & $.019 \times .025$-in stainless steel archwire & 10 & 10 & ORTHO SYSTEM \\
\hline & $.019 \times .025$-in stainless steel archwire & 10 & 10 & $\mathrm{AO}$ \\
\hline & $.019 \times .025$-in stainless steel archwire & 10 & 10 & $\mathrm{G} \& \mathrm{H}$ \\
\hline & $.016 "$-in nickel-titanium archwire & 10 & 10 & ORTHOSYSTEM \\
\hline & $.016 "$-in nickel-titanium archwire & 10 & 10 & $\mathrm{AO}$ \\
\hline & $.016 "$-in nickel-titanium archwire & 10 & 10 & $\mathrm{G} \& \mathrm{H}$ \\
\hline 2. & Molar bands & 10 & 10 & $\begin{array}{l}\text { MODERN } \\
\text { ORTHODONTICS }\end{array}$ \\
\hline 3. & Stainless steel orthodontic brackets & 10 & 10 & $\begin{array}{l}\text { MODERN } \\
\text { ORTHODONTICS }\end{array}$ \\
\hline 4. & Coil spring & 10 & 10 & $\mathrm{AO}$ \\
\hline 5. & Elastomeric modules & 10 & 10 & $\mathrm{AO}$ \\
\hline 6. & Tungsten carbide burs & 10 & 10 & SS White \\
\hline 7. & E-chain & 10 & 10 & $\mathrm{AO}$ \\
\hline
\end{tabular}
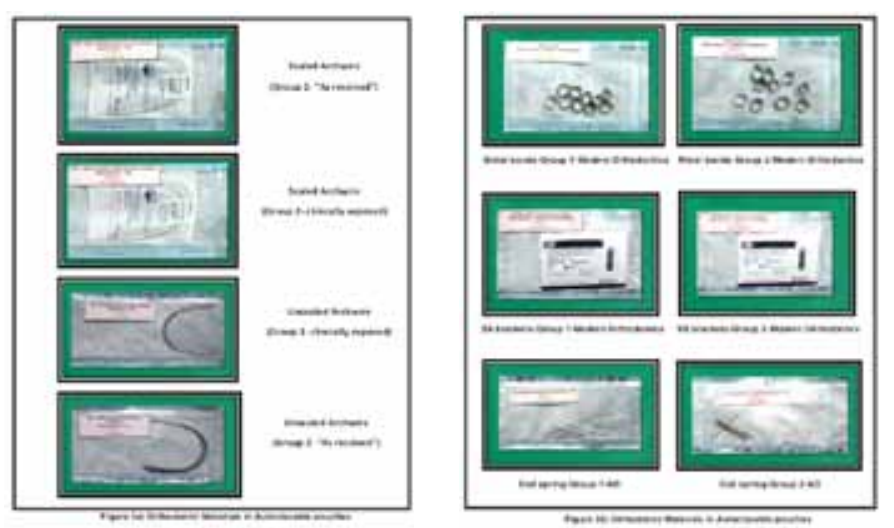

Figure $3 a, 3 b, 3 c$.

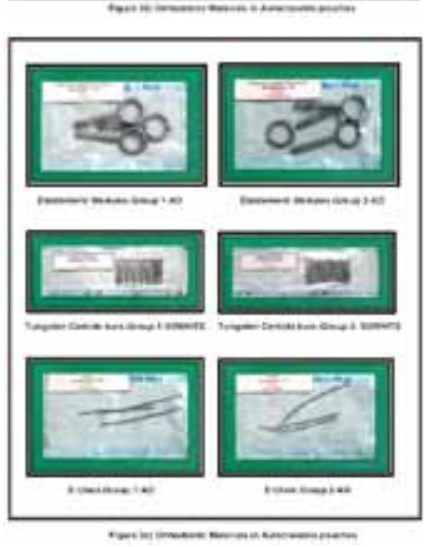

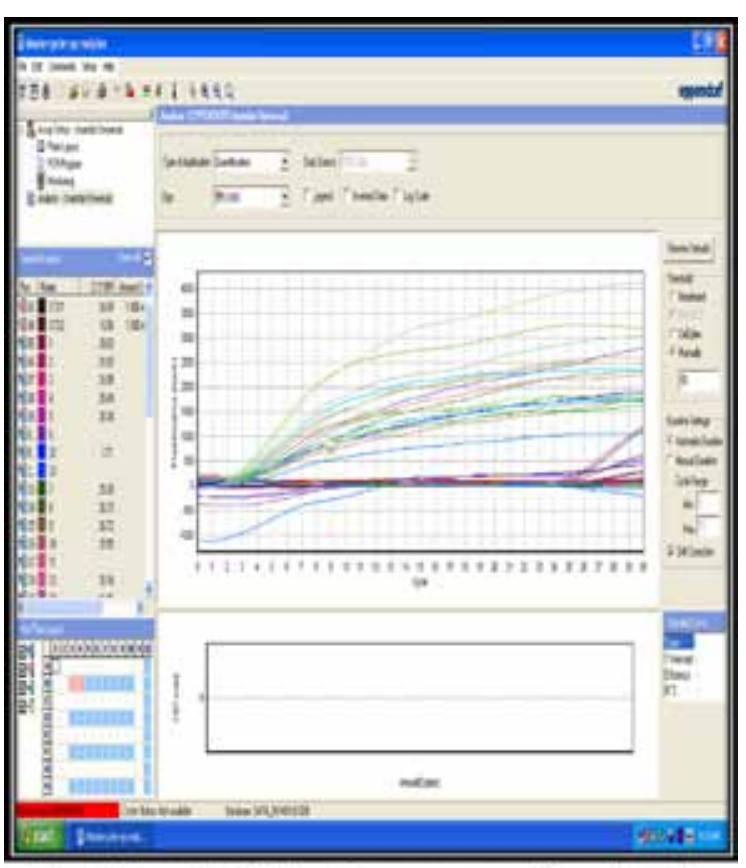

Figure 4.

devised to detect the target species/phylotypes in a sample. Universal organisms were detected or amplified by Real-time PCR whereas Actinomyces, Lactobacillus, Staphylococcus and Streptococcus were amplified separately by conventional PCR. Real-time PCR for universal organisms was recorded by the Realplex software of the thermal cycler. (Figure 4) In Conventional PCR, each PCR amplicons were separated by electrophoresis on a $2 \%$ agarose gel. The gel images were captured using a gel doc system (Figure 5a, 5b).

The materials which were included in this study are the orthodontic archwires, molar bands, elastomeric module, stainless steel bracket, coil spring and tungsten carbide burs. (Figure 1a, 1b, 1c and Table 1)
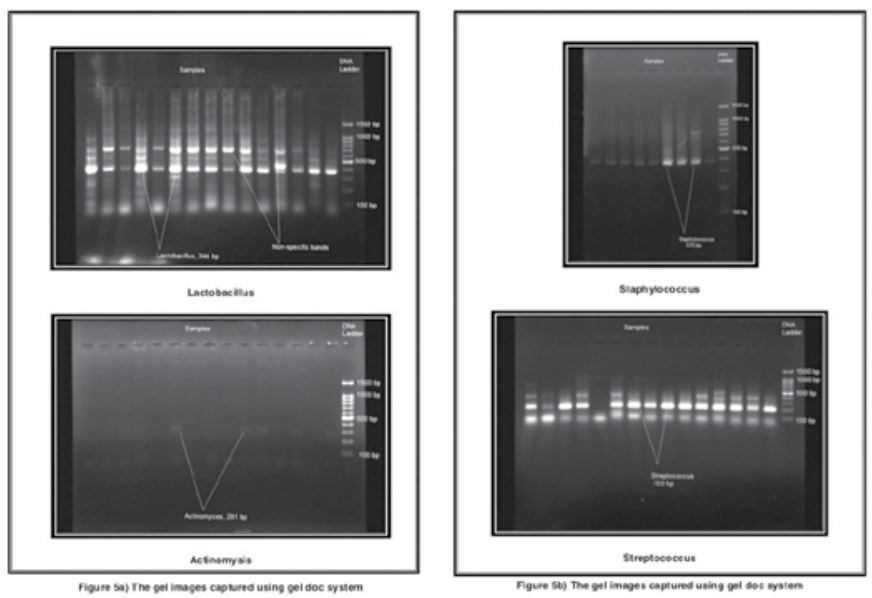

Figure $5 a, 5 b$. 
Orthodontic archwires were further classified into sealed and unsealed (from three different manufacturers which are available). Sealed and unsealed wires were taken for these studies are stainless steel wires and $\mathrm{Ni}-\mathrm{Ti}$ wires. The manufacturer taken for sealed wires are $3 \mathrm{M}$ Unitek, Ormco and American Orthodontics (AO), and the manufacturers for unsealed wires are Orthosystems, American Orthodontics and G\&H. 10 of each item was studied as a sample size which was appropriate for this study. (Figure 1a and Table 1)

Ten samples of molar bands (modern orthodontics), elastomeric modules (American orthodontics) and coil springs (American Orthodontics), stainless steel orthodontic brackets (Modern Orthodontics) and tungsten carbide burs (SS White), e-chains (American Orthodontics) for both group 1 and group 2 were also taken. (Figure $1 \mathrm{~b}, 1 \mathrm{c}$ and Table 1 )

\section{Statistical analysis}

The statistical significance of difference for detection of organisms between as received samples and clinically exposed samples is carried out using Wilcoxon's signed rank test. The statistical significance of difference for detection of microorganisms between sealed and unsealed samples is carried out using Mann-Whitney $U$ test. The entire data was entered and cleaned in MS Excel before its statistical analysis.

The P-values less than 0.05 are considered to be statistically significant. All the hypotheses re-formulated using twotailed alternatives against each null hypothesis (hypothesis of no difference). The entire data is statistically analyzed using Statistical Package for Social Sciences (SPSS ver 11.5, Inc. Chicago, USA) for MS Windows.

\section{RESULTS}

Results of universal and conventional PCR in "as received" (Group 1) and "clinically exposed" after six months (Group 2) are listed in table 2 and table 3 respectively.

1. The overall detection of micro-organisms in orthodontic materials:

a. The detection of micro-organisms in all materials is significantly higher in the clinically exposed samples compared to as received samples from manufacturers ( $P$ $<0.001)$.

2. The overall detection of micro-organisms in sealed and unsealed orthodontic archwires:

a. The detection of micro-organisms in all orthodontic wires is significantly higher in the unsealed samples compared to sealed samples $(\mathrm{P}<0.001)$.

3. Detection of micro-organisms in sealed orthodontic archwires:

a. In universal PCR, the detection of micro-organisms in all orthodontic sealed wires of brand ORMCO (SS and NiTi) and AO (SS and NITI) is significantly higher in the clinically exposed samples compared to as received samples $(\mathrm{P}<0.001)$.

b. In conventional PCR, the detection of lactobacillus microorganisms in all orthodontic sealed wires of brand 3M (SS) and AO (NITI) are significantly higher in both as received and clinically exposed samples.

c. Also, the detection of staphylococci in all orthodontic sealed wires of brand $3 \mathrm{M}(\mathrm{NITI})$, and $\mathrm{AO}$ (NITI) was significantly higher in clinically exposed samples $(\mathrm{P}<0.001)$.

d. In conventional PCR, the detection of staphylococci in all orthodontic sealed wires of brand AO (SS), ORMCO (SS), 3M (NITI) was significantly higher in both as received and clinically exposed samples. Also, the detection of staphylococci in all orthodontic sealed wires of brand $3 \mathrm{M}$ (SS), and ORMCO (NITI) was significantly higher in clinically exposed samples $(\mathrm{P}<0.001)$.

e. In conventional PCR, the detection of Streptococcus microorganisms in all orthodontic sealed wires of brand $\mathrm{AO}$ (SS), AO (NITI) and ORMCO (NITI) was significantly higher in both as received and clinically exposed samples. Also, the detection of Streptococcus micro-organisms in all orthodontic sealed wires of brand 3M (SS), ORMCO (NITI), 3M (NITI) was significantly higher in clinically exposed samples $(\mathrm{P}<0.001)$.

4. Detection of micro-organisms in unsealed orthodontic archwires:

a. In universal PCR, the detection of micro-organisms in all orthodontic unsealed wires of all brands was significantly higher in both as received and clinically exposed samples.

b. In conventional PCR, the detection of lactobacillus microorganisms in all orthodontic unsealed wires of brand ORTHOSYSTEMS (SS), AO (SS), G\& H (SS) and AO (NiTi) was significantly higher in clinically exposed samples $(\mathrm{P}<0.001)$.

c. In conventional PCR, the detection of actinomyces microorganisms in all orthodontic unsealed wires of brand G \& $\mathrm{H}$ (SS and $\mathrm{NiTi}$ ) is significantly higher in clinically exposed samples compared to as received samples $(\mathrm{P}<0.001)$. Also, the detection of actinomyces micro-organisms in all orthodontic unsealed wires of brand $\mathrm{AO}(\mathrm{NiTi})$ was significantly higher in both as received and clinically exposed samples.

d. In conventional PCR, the detection of staphylococci in all orthodontic unsealed wires of brand ORTHOSYSTEMS (SS and $\mathrm{NiTi}$ ), AO (SS), G\&H (SS and NiTi) was significantly higher in both as received and clinically exposed samples.

e. In conventional PCR, the detection of Streptococcus micro-organisms in all orthodontic unsealed wires of brand ORTHOSYSTEMS (SS and NiTi), AO (SS), G\&H (SS and $\mathrm{NiTi}$ ) was significantly higher in both as received and clinically exposed samples. Also, the detection of Streptococcus micro-organisms in all orthodontic unsealed wires of brand $\mathrm{AO}(\mathrm{NiTi})$ was significantly higher in clinically exposed samples $(\mathrm{P}<0.001)$.

5. Detection of micro-organisms in orthodontic materials (except wires):

a. In universal PCR, the detection of micro-organisms in all materials (Coil spring, E-chain, Elastomeric, Molar brands, Tungsten carbide) except for SS brackets is significantly higher in both as received and clinically exposed samples. 
b. In universal PCR, for SS brackets, the detection of organisms is significantly higher in clinically exposed samples compared to as received samples $(\mathrm{P}<0.001)$.

c. In conventional PCR, the detection of lactobacillus microorganisms in all materials was significantly higher in E-chain, Elastomeric modules, molar bands in both as received and clinically exposed samples.

d. In conventional PCR, the detection of actinomyces microorganisms was significantly higher in Coil springs, molar bands in both as received and clinically exposed samples.

e. In conventional PCR, the detection of Staphylococcus micro-organisms was significantly higher in molar bands, SS brackets, tungsten carbide burs in both as received and clinically exposed samples. Also, the detection of Staphylococcus micro-organisms was significantly higher in E-chains, Elastomeric modules in clinically exposed samples.

f. In conventional PCR, the detection of Streptococcus microorganisms was significantly higher in Coil springs, E-chains, Elastomeric modules, molar bands, tungsten carbide burs and SS brackets in both as received and clinically exposed samples.

Intra-Group Comparisons for materials except for archwires (Universal PCR)

1) For brands of all materials (except for SS brackets), the detection of organisms did not differ significantly between before and after clinical exposed samples ( $\mathrm{P}>0.05$ for all).

2) For SS brackets, the detection of organisms was significantly higher in clinically exposed samples compared to as received samples $(\mathrm{P}<0.001)$.

Intra-Group Comparison for materials except for archwires (Conventional PCR)

\section{1) Detection of Lactobacillus organism}

a. For all brands of all materials, the detection of organisms did not differ significantly between before and after in clinically exposed samples ( $\mathrm{P}>0.05$ for all).

\section{2) Detection of Actinomyces organism}

a. For all brands of all materials, the detection of microorganisms did not differ significantly between before and after clinical exposure of samples ( $\mathrm{P}>0.05$ for all).

\section{3) Detection of Staphylococcus organism}

a. For AO brand of E-chain and Elastomeric materials, the detection of organisms differed significantly between before and after clinical exposure of samples ( $\mathrm{P}<0.001$ for both).

\section{4) Detection of Streptococcus organism}

a. For all brands of all materials, the detection of microorganisms did not differ significantly between before and after clinical exposed samples ( $\mathrm{P}>0.05$ for all).

\section{DISCUSSION}

In orthodontic clinical practice, materials like molar bands, archwires, brackets, elastomeric modules, etc. are used directly in patients from manufacturers' packaging under the assumption that they are sterile although the manufacturers might not state this. Due to this, it becomes extremely important to assess the potential contamination of these materials to determine sterilization protocols and maintain the health of patients and dental professionals. ${ }^{5}$ There are two approaches to identify and classify oral bacteria, first technique that requires culturing of the organisms and other by a molecular technique that does not require culturing which we followed in our study. DNA was extracted with Modified Proteinase-K method given by Vanpelt E, Belkum VAV and Hays JP. ${ }^{6}$ This is the newer approach for lysis of the bacterial cell. Preparation of bacterial DNA for molecular analysis after lysis can be accomplished by polymerase chain reaction (PCR), which helps to determine even minute quantities of bacteria. Studies have shown high sensitivity and reliability of these machines in detecting bacteria even to a 2 -fold change in the bacterial count. ${ }^{7}$ Few studies have evaluated the sterility of orthodontic materials like brackets, molar tubes with polymerase chain reaction. Gerzson et al. studied the sterility of brackets by biochemical tests and confirmed by DNA extraction and PCR. Purmel et al. studied the microbial contamination of orthodontic buccal tubes from manufacturers by the procedure of DNA Extraction, PCR and sequencing. ${ }^{8}$ Orthodontic materials can be considered as semi-critical medical instruments that require a high level of disinfection. ${ }^{9}$ Lucas et al. have demonstrated that orthodontic treatment procedures can cause bacteremia by aerobic and anaerobic bacteria. ${ }^{10}$ There is a clear guideline on the sterilization requirements for any material or instrument that comes into contact with human tissues, including those of dental use. ${ }^{11}$ Orthodontic archwires are an integral part of the fixed appliance used for the treatment of orthodontic malocclusions. Results from both universal and conventional PCR conclude that, in "as received" sealed and unsealed archwires, all manufacturers showed bacterial contamination. This data suggests that orthodontist should use the recommended method of disinfection or sterilization before their use in the orthodontic clinic for the security of patient health. Manufacturers of archwires should improve the quality of the packaging used. Only ORMCO had given instructions on their packages. They have mentioned that the wire has been individually packaged to reduce cross-contamination and if additional protection is desired this package and its contents can be sterilized through an autoclave. In another aspect of this study evaluation of whether storage of this "as received" archwires in the clinical environment affect the sterility or not was done and we concluded that all three manufacturers of sealed archwires, all brands (AO, ORMCO and $3 \mathrm{M})$ were contaminated with bacteria after exposure to the clinical environment. Also, some sealed wires showed micro-organisms significantly higher in clinically exposed samples compared to as received samples.

The correct storage protocol of unused stored materials is also important to protect them from environmental contamination. Instrument cassettes and instrument packs must be kept in such a way that contamination from splashes and aerosols does not occur. As compared to other materials molar bands showed more 
bacterial contamination, indicating disinfection or sterilization before their use. Banding is frequently done on the posterior teeth during fixed appliance treatment where several attempts may be required to achieve the correct size. There is no literature found on sterility of molar bands on "as received" from the manufacturer and on stored unused molar bands. In previous studies, a lot of attention has been focused on sterilization of molar bands for both the tried-in bands as well as the new bands. ${ }^{12}$ It is recommended to sterilize the tried-in molar bands separately without mixing them up with the new ones. If the tried-in molar bands cannot be sterilized immediately, it is advisable to process them through a pre-sterilization cleaning procedure with ultrasonic scaling and storing them separately. ${ }^{13}$

Elastomeric chains are among the different types of materials that highly favor the occurrence of cross-infection and that are very sensitive to different processes of sterilization. ${ }^{14}$ E-chain of all samples showed bacterial contamination. (Graph 1,2) Usually, the elastomeric chain is cut off from the roll with a scissor and inserted in the oral cavity without being submitted to any process of disinfection or sterilization. Elastomeric chain material can be contaminated during processing, packaging and manipulation by the dental assistant or orthodontist. At the time of inserting them into a patient's oral cavity, the orthodontist indirectly contaminates the reel that contains the material which may trigger cross-infection. Pithon MM et al. found that except for the ultraviolet method, all other methods promoted sterilization of elastomeric chains; no sterilization methods led to a loss of elastomeric chains mechanical properties. ${ }^{15}$ The application of $\mathrm{Ni}$ Ti coil springs has been popular in the fixed orthodontic treatment. In this study, we evaluated the sterility of NiTi coil springs of both the groups. Coil springs of all samples (i.e., as received and after exposed to clinic environment) showed bacterial contamination. (Graph 1,2) There are limited studies performed about the effects of sterilization and recycling on the mechanical properties of coil springs. ${ }^{16,17}$ Dental burs used during various procedures some of which includes caries excavation, access cavity preparation and crown reduction may become heavily contaminated with necrotic tissue, saliva, blood and potential pathogens and identified as the potential vehicle for cross infection. ${ }^{18}$ All the burs showed significantly high microbial contamination. (Graph 1,2) The most commonly used methods of sterilization include soaking of burs in commercially available disinfectors followed by manual cleaning, using an ultrasonic bath or autoclaving, dry heat oven, glass bead sterilization. ${ }^{19,20,21}$ Several products are available for disinfecting and sterilizing instruments (e.g., orthodontic pliers), but data on the microbial contamination of orthodontic brackets as supplied by the manufacturers are lacking in the literature. The Stainless steel brackets in our study showed high contamination in clinically exposed samples compared to as received samples and also staphylococci and streptococci were significantly high. (Graph 1,2) Elastomeric modules are one of the most popular components in orthodontic practice because of the ease in application and cost efficiency. Numerous studies have been conducted to evaluate their strength, in terms of force delivery and rate of force decay in various environments. However, there is a lack of data on the microbial contamination of elastomeric modules as supplied by the manufacturers. ${ }^{22}$ The data suggest that after universal and conventional PCR, Elastomeric modules of all samples (i.e., as received and after exposed to clinic environment) showed bacterial contamination. (Graph 1,2) Other than those materials which were used in the present study, previous data confirm the sterility of orthodontic molar tubes "as received" from manufacturers. Purmal et al. evaluated the microbial contamination of buccal tubes from a manufacturer and after DNA extraction, PCR and sequencing and found that some buccal tubes received from the manufacturer were contaminated with aerobic bacteria. They conclude that microbial contamination of buccal tubes highlights the need of sterilization before clinical use, which makes the need from the manufacturer to list the sterility state of orthodontic buccal tubes on their packaging. The authors suggested that the presence of the bacteria could result from unhygienic practices during material manufacturing and packaging, justifying the results of this study. ${ }^{8}$ With regards to the pathogenicity of microorganisms, Andrucioli et al. had already underscored that high levels of oral microorganisms increase not only the risk of caries and periodontal disease but also of systematic complications. ${ }^{23}$ The sterility of orthodontic materials can be breached through many ways on the way from the manufacturer to the dental office and the extended storage of these materials in the clinical environment. Examination of the different species of bacteria isolated in the present and previous studies have shown that oral bacteria were found from unused items; this is interesting since the method of transmission must be related to many factors.

The manufacturers of orthodontic materials used in our study did not have any labeling concerning sterility of the product. The packaging labels also did not have any suggestion whether these materials should be sterilized before clinical use. All these materials were packaged in a sealed plastic container; however, the majority of them were not protected from the external environment by their packaging. Therefore, it is possible that contamination occurred during the manufacturing process and during transport from the manufacturers to the dental clinics or from repackaging by the local distributors. Storage of materials in the clinical environment also plays a major role in maintaining the sterility of materials. It is mostly concerned with sterilization and disinfection protocols following in dental offices. While considering the enormity of the challenge that infectious agents pose against us and their nature to continuously evolve in real time. The implementation and execution of effective sterilization protocols of all orthodontic materials before use in patients is vital. Keeping this in mind the study was meant to eliminate those entire drawbacks which were present in past work. The uniqueness in our study is its vastness in material coverage and use of highly sophisticated and accurate molecular tests, which was not possible in the past. 


\section{CONCLUSION}

After universal and conventional PCR, we conclude that bacteria were present on almost all orthodontic materials "as received from the manufacturers" and that exposed to clinical environment. Therefore all materials should be sterilized before use in patients.

1. In sealed and unsealed archwires we conclude that sealed wires showed less microbial contamination than unsealed wires. As sealed wires have been individually packaged to reduce crosscontamination and if additional protection is desired this package and its contents may be sterilized by autoclave.

2. In sealed wires, brands of AO and ORMCO showed less microbial contamination with good quality of packaging than 3M Unitek. However, after conventional PCR we found that these items are also not sterile so clinicians should follow proper protocols of disinfection or sterilization, before their use in the orthodontic clinic for the safety of patient health.

3. In the present study it was seen that except sealed ORMCO manufacturer, the packaging labels also did not have any suggestion whether these materials should be sterilized before clinical use. The manufacturers of these materials should improve the quality of packaging used, including instituting effective protocols, or that clinicians should use a method of disinfection or sterilization, before their use in the orthodontic clinic for the security of patient health.

4. We postulate that the presence of these bacteria is due to unhygienic practices of staff at the production line during manufacturing and packaging. We also speculate that the nonsterile packaging and improper handling of packages can also be a source of the bacterial contamination especially during logistics and storage of orthodontic materials.

5. Therefore it is concluded that the manufacturers should state the sterility of their products and for practitioners should ensure the sterility of materials before use and not to assume that all items are sterile.

\section{Graph 1.}

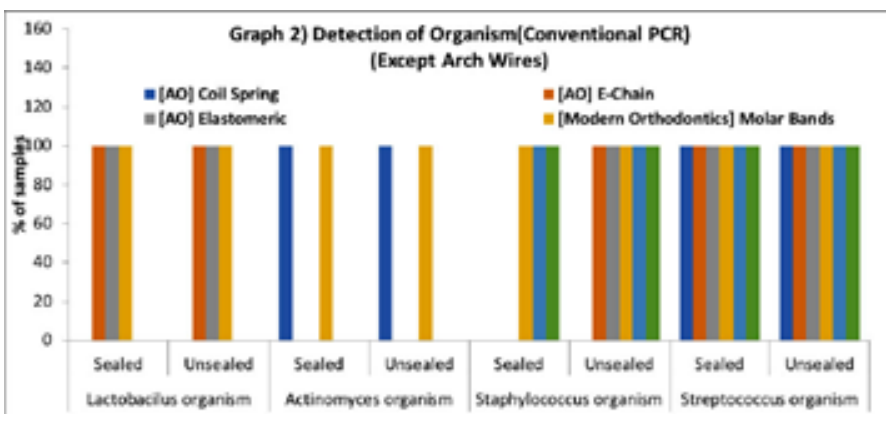

Graph 2.

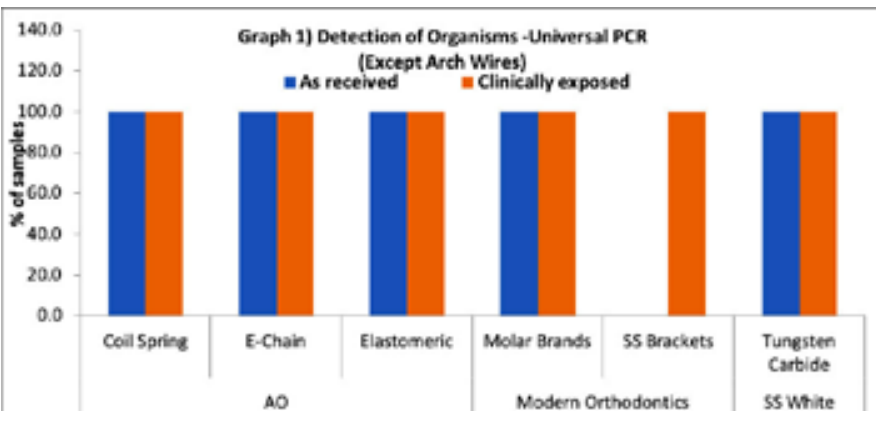

Table 2. Detection of organisms in group 1- "as received"

\begin{tabular}{|c|c|c|c|c|c|c|}
\hline \multirow{2}{*}{ Sr No } & \multirow{2}{*}{ Group I Samples } & \multicolumn{5}{|c|}{ Results } \\
\hline & & Universal & Lactobacillus & Actinomyces & Staphylococcus & Streptococcus \\
\hline & $\begin{array}{l}\text { 1. Archwires } \\
\text { a. Sealed archwires }\end{array}$ & & & & & \\
\hline $\mathrm{A} 3$ & $.019 \times .025 \mathrm{SS}-\mathrm{AO}$ & - & - & - & + & + \\
\hline $\mathrm{F} 1$ & $.019 \times .025$ SS - ORMCO & - & - & - & + & - \\
\hline $\mathrm{F} 2$ & $019 \times .025$ SS - 3M Unitek & + & + & - & - & - \\
\hline $\mathrm{A} 1$ & $.016 " \mathrm{NiTi}-3 \mathrm{M}$ Unitek & + & - & - & + & - \\
\hline $\mathrm{A} 2$ & $.016 ” \mathrm{NiTi}-$ ORMCO & - & - & - & - & + \\
\hline F3 & $.016 " \mathrm{NiTi}-\mathrm{AO}$ & - & + & - & - & + \\
\hline & b. Unsealed archwires & & & & & \\
\hline B4 & $.019 \times .025$-SS-Orthosystem & + & - & - & + & + \\
\hline B5 & $.019 \times .025 S S-A O$ & + & - & - & + & + \\
\hline B6 & $.019 \times .025$ SS- G \& H & + & - & - & + & + \\
\hline B1 & 016” NiTi-Orthosystem & + & - & - & + & + \\
\hline B2 & $.016 " \mathrm{NiTi}-\mathrm{AO}$ & + & - & + & - & - \\
\hline B3 & $.016 " \mathrm{NiTi}-\mathrm{G} \& \mathrm{H}$ & + & - & - & + & + \\
\hline D5 & Molar bands & + & + & + & + & + \\
\hline D6 & SS orthodontic brackets & - & - & - & + & + \\
\hline D3 & Coil spring & + & - & + & - & + \\
\hline D2 & Elastomeric modules & + & + & - & - & + \\
\hline D4 & Tungsten carbide burs & + & - & - & + & + \\
\hline D1 & E-chain & + & + & - & - & + \\
\hline
\end{tabular}


Table 3. Detection of Organisms in group 2- "linically exposed"

\begin{tabular}{|c|c|c|c|c|c|c|}
\hline \multirow{2}{*}{ Sr No } & \multirow{2}{*}{ Group I Samples } & \multicolumn{5}{|c|}{ Results } \\
\hline & & Universal & Lactobacillus & Actinomyces & Staphylococcus & Streptococcus \\
\hline \multicolumn{7}{|c|}{$\begin{array}{l}\text { 1. Archwires } \\
\text { a. Sealed archwires }\end{array}$} \\
\hline G2 & $.019 \times .025-\mathrm{SS} \mathrm{AO}$ & + & - & - & + & + \\
\hline G1 & $.019 \times .025$-SS Ormco & + & - & - & + & + \\
\hline G3 & $019 \times .025-S S 3 M$ & + & + & - & + & + \\
\hline $\mathrm{C} 1$ & $.016 "$-NiTi 3M Unitek & + & - & + & + & + \\
\hline $\mathrm{C} 2$ & $.016^{\prime \prime}$-NiTiOrmco & + & - & - & + & + \\
\hline G7 & $.016 "-\mathrm{NiTi} \mathrm{AO}$ & + & + & + & - & + \\
\hline \multicolumn{7}{|c|}{ b. Unsealed archwires } \\
\hline G8 & $.019 \times .025$-SS Orthosystem & + & + & - & + & + \\
\hline G4 & $.019 \times .025-\mathrm{SS}$ AO & + & + & - & + & + \\
\hline $\mathrm{C} 4$ & $.019 \times .025-S S$ G \& H & + & + & + & + & + \\
\hline G6 & 016" -NiTiOrthosystem & + & - & - & + & + \\
\hline G5 & $.016 "-\mathrm{NiTi} \mathrm{AO}$ & + & + & + & - & + \\
\hline $\mathrm{C} 3$ & $.016 "$-NiTi G \& H & + & - & + & + & - \\
\hline E5 & Molar bands & + & + & + & + & + \\
\hline E6 & 3. Stainless steel orthodontic brackets & + & - & - & + & + \\
\hline E3 & Coil spring & + & - & + & - & + \\
\hline E2 & Elastomeric modules & + & + & - & + & + \\
\hline E4 & Tungsten carbide burs & + & - & - & + & + \\
\hline E1 & E-chain & + & + & - & + & + \\
\hline
\end{tabular}

+ : Presence of bacteria $\quad-:$ Absence of bacteria

Conflict of interest: none declared

\section{REFERENCES}

1. Mahboobi N, Agha-Hosseini F, Mahboobi N, Safari S, Lavanchy D, Alavian SM. Hepatitis B virus infection in dentistry: a forgotten topic. J Viral Hepat. 2010;17(5):307-16.

2. Scully C, Greenspan JS. Human immunodeficiency virus (HIV) transmission in dentistry. J Dent Res. 2006;85(9):794-800.

3. Reddy VP, Reddy GY, Hegde N, Priyadarshini A. Sterilization methods in orthodontics-A Review. Int J Dent Clin. 2011;3(1):44-47.

4. Serdar Toroglu M, Bayramoglu O, Yarkin F, Tuli A. Possibility of blood and hepatitis B contamination through aerosols generated during debonding procedures. Angle Orthod. 2003;73(5):571-8.

5. Dos Santos Gerzson DR, Simon D, Dos Anjos AL, Freitas MP. In vitro evaluation of microbial contamination of orthodontic brackets as received from the manufacturer using microbiological and molecular tests. Angle Orthod. 2015;85(6):992-6.

6. Vanpelt E. Principles and Technical aspects of PCR amplification. Springer 2008;34.

7. Joshi M, Deshpande JD. Polymerase Chain Reaction: Methods, principles and application. Int J Biomed Res 2010;1(5):81-97.

8. Purmal K, Chin S, Pinto J, Yin WF, Chan KG. Microbial contamination of orthodontic buccal tubes from manufacturers. Int J Mol Sci 2010;1 1:3349-56.

9. Kohn WG, Collins AS, Cleveland JL, Harte JA, Eklund KJ, Malvitz DM. Guidelines for infection control in dental health-care settings-2003. Available from: https://stacks.cdc.gov/view/cdc/6743/cdc_DS1_6743

10. Lucas, VS, Omar J, Vieira A, Roberts GJ. The relationship between odontogenic bacteremia and orthodontic treatment procedures. Eur J Orthod. 2002;24:293-301.

11. Miller $\mathrm{CH}$, Palenik CJ. Infection control and management of hazardous materials for the dental team, 2nd ed.; Mosby Building Arts: St. Louise, MO, USA, 1998.

12. Smith GE. Glass bead sterilization of orthodontic bands. Am J of Orthod Dentofacial Orthop 1986;90(3):243-249.
13. Dowsing P, Benson P. Molar band re-use and decontamination: a survey of specialists. J Orthod 2006;33(1):30-7.

14. Jeffries CL, von Fraunhofer JA. The effects of $2 \%$ alkaline glutaraldehyde solution on the elastic properties of elastomeric chain. Angle Orthod 1991;61:25-30.

15. Pithon MM, Ferraz CS, Rosa FCS, Rosa LP. Sterilizing elastomeric chains without losing mechanical properties. Is it possible? Dental Press J Orthod. 2015;20(3):96-100.

16. Wichelhaus A, Brauchli L, Ball J, Mertmann M. Mechanical behaviour and clinical application of nickel-titanium closed-coil springs under different stress levels and mechanical loading cycles. Am J Orthod Dentofacial Orthop. 2010;137: 671-678.

17. Vidoni G, Perinetti G, Antoniolli F, Castaldo A, Contardo L. Combined aging effects of strain and thermocycling on unload deflection modes of nickeltitanium closed-coil springs: an in-vitro comparative study. Am J Orthod Dentofacial Orthop 2010;138:451-457.

18. Sajjanshetty S, Hugar D, Hugar S, Ranjan S, Kadani M. Decontamination methods used for dental burs-a comparative study. J Clin Diagn Res. 2014;6(8):ZC39-ZC41.

19. Sheriteh Z, Hassan T, Sherriff M, and Cobourne M. Decontamination procedures for tungsten carbide debonding burs: a cross sectional survey of hospital based orthodontic departments. J Orthod .2010;37(3):174-80.

20. Schutt RW, Starsiak WJ. Glass bead sterilization of surgical dental burs. Int J Oral Maxillofac Surg.1990;19:250-1.

21. Whitworth CL, Martin MV, Gallagher M, Worthington HV. A comparison of decontamination methods used for dental burs. Br Dent J 2004;197:635-40.

22. Evangelista MB., Berzins DW, Monaghan P. Effect of disinfecting solutions on the mechanical properties of orthodontic elastomeric ligatures. Angle Orthod 2007;77(4):681-687.

23. Andrucioli MCD, Nelson-Filho P, Matsumoto MAN. Molecular detection of invivo microbial contamination of metallic orthodontic brackets by checkerboard DNA-DNA hybridization. Am J Orthod Dentofacial Orthop. 2012;141:24-29. 